\section{Will less actually be more?}

\section{Bethesda, Maryland}

HoPING to simplify the tangled system by which US universities account for their government-related research overhead expenses, officials are considering acrossthe-board limits that could return more than $\$ 65$ million per year to biomedical research.

At a meeting last week, an advisory panel to Bernadine Healy, director of the National Institutes of Health $(\mathrm{NIH})$, proposed three different options for major reforms. All of the alternatives would cut out much of the accounting in favour of simple formulas or fixed limits, something that reflects the general opinion that the indirect cost overcharges are due more to the complexity of the system than to conspiracy. Notably, all the options (see box, this page) would reduce the amount that universities can charge as research overhead, on the argument that most universities would be willing to sacrifice a little reimbursement if they could eliminate the accounting morass.

Since the indirect cost scandal broke last spring, administration officials have been racing to put reforms in place, lest Congress do it for them. In May, the administration imposed a 26 per cent limit on the administrative portion of indirect costs as a stop-gap measure, promising to do more after further analysis. At the time, officials said this cap would save the government more than $\$ 100$ million a year (see Nature 350, 642; 25 April 1991). But the latest accounting, released last week, estimates that the saving will only be about $\$ 55$ million. NIH pays out about $\$ 1,600$ million each year for indirect costs.

Congress will be looking closely at the President's 1993 budget request for evidence of more substantial and lasting reforms. As that document is expected around the end of January, administration officials have just a month or so to reach consensus on new procedures. NIH are just one of several agencies participating in the reform process, but because NIH have the largest slice of the research pie, Healy's recommendations are expected to carry some weight.

At the moment, Healy and many of her advisers appear to favour the option of a simple formula or a flat rate to determine costs. One of last week's proposals is to set either an allowable indirect cost rate based on the size, type and geographic location of a university, or else a flat rate of 48 per cent, across the board. At present, universities average a 51 per cent indirect cost rate, based on rates at each university that are arrived at by arcane calculations and long negotiations with government auditors. The advisory panel argued that eliminating that process should save much of the accounting overhead of research and would compensate for the cut in the overall rate, which would save $\$ 65.6$ million that could be used to fund 289 new research grants.

Whether this administration can be the one to finally fix the indirect cost system once and for all remains to be seen. University groups argue against wholesale change. "You really can't just scrap the whole thing and start fresh," says David Moore of the Association of American Medical Colleges. "You've got a huge research system out there that could collapse." Already many universities, squeezed by state budget cuts and tuition caps, are being forced to turn down research grants with low indirect cost limits (such as those from the Department of Agriculture, which are limited to 14 per cent) because they cannot afford to cover the overhead, he says.

But others argue for a shake-up all the same, despite the risk of teething pains. They point out that, unlike government contracts, where institutions do what the government wants in return for a fixed fee, research proposals come from univer-

\section{NIH's options}

- Simplified accounting. Universities that do less than $\$ 3$ million a year in government research are now allowed to use a short form to calculate their indirect cost rate, without elaborate accounting and negotiating. That cutoff could be increased to $\$ 10$ million, which would allow many more universities to go the 'EZ form' route. Potential savings: $\$ 72$ million.

- Formulas or fixed rates. Rather than negotiate rates on a case-by-case basis, universities could use a common formula based on their size, geographic location and public or private status. Or the government could do away with the whole process and go for a fixed 48 per cent rate, slightly under the current average. Potential savings: Between $\$ 13$ million and $\$ 44$ million depending on the formula used, or $\$ 66$ million for a fixed rate.

- Caps. Currently only the administrative portion of indirect costs is capped, at 26 per cent. That limit could be reduced to 20 per cent, library costs could be limited to two per cent, and student services charges could be eliminated. Potential savings: $\$ 117$ million.

C.A.

sity scientists and benefit the institution as much as the government.

Indeed, the idea that universities deserve 'full-cost recovery' actually dates from wartime emergency rules, says John Holmfeld, a long-time congressional staff member who is now executive director of the Council of Scientific Society Presidents. Before the Second World War, universities were usually not given extra money to cover the incidental expenses of doing government-funded research. But during the war, the government asked universities to do special research in the national interest, and agreed to cover the extra costs. After the war, "it never stopped." Christopher Anderson

\title{
The case of the amazing shrinking scandal
}

Washington

REMEMBER the reports of tens and even hundreds of million dollars that US universities had improperly charged to research overhead? Nature reported those figures (350, 182; 21 March 1991 \& 351, 173; 16 May 1991) and so did nearly everyone else. But last month government investigators released the results of a year-long audit and the problem appears to have been exaggerated - by a factor of ten or more.

The audit of 14 major US research universities found a total of between $\$ 1.9$ million and $\$ 2.4$ million in costs that universities had improperly charged the government in the year examined. This is out of $\$ 1,733$ million in government research, or a bit more than 0.1 per cent. By accounting standards, that is not much. "Maybe it initially looked like a scandal," says Howard Gobstein of the Association of American Universities, "But we're finding out that the [accounting] system actually works pretty well."

So where did the big numbers come from? Part of the answer can be found in the complexity of indirect cost accounting. Just because a university may have improperly charged vast sums to government research accounts does not mean that it actually billed the government for those amounts. Only a portion of the charges will fall under the category of billable research, and only a portion of research funding can be recovered as overhead. In last month's audit, investigators found about $\$ 26$ million of improper costs. But about half of that was voluntarily withdrawn, and most of the rest was not research-related. That left only $\$ 3.2$ million classified as researchrelated. Since each of the universities in the audit was given an allowable indirect cost rate of between 60 and 75 per cent, they actually overcharged the government for only about $\$ 2$ million total. C.A. 